\title{
Measurement of urinary 5-HIAA: correlation between spot versus 24-h urine collection
}

\author{
Matilde Calanchini ${ }^{1,2}$, Michael Tadman ${ }^{1}$, Jesper Krogh ${ }^{1}$, Andrea Fabbri², Ashley Grossman ${ }^{1}$ and Brian Shine ${ }^{1}$ \\ ${ }^{1}$ Oxford Centre for Diabetes, Endocrinology \& Metabolism, Churchill Hospital, University of Oxford, Oxford, UK \\ ${ }^{2}$ Endocrinology \& Metabolism Unit, CTO A. Alesini Hospital ASL Roma 2, Department of Systems Medicine, University of Rome Tor Vergata, Rome, Italy
}

Correspondence should be addressed to M Calanchini: matimat79@gmail.com

The authors and journal apologise for an error in the above paper, which appeared in volume 8 part 8, pages 1082-1088. The error relates to the unit of measurement for 5-hydroxyindoleacetic acid (5-HIAA), which was given as mol/mmol. The correct unit of measurement should be $\mu \mathrm{mol} / \mathrm{mol}$.

The error was present in the Abstract on page 1082, in the Results section on page 1084-1085, in the Discussion section on page 1086, and in the artwork and text legend of Fig. 1.

In the Abstract on page 1082, the original article stated:

'Using the 24-h urinary 5-HIAA as reference method, the AUC on ROC analysis for spot urinary 5-HIAA was 0.948 (95\% CI, $0.914-0.983 ; P<0.001$ ), attaining a sensitivity of $83 \%$ and specificity of $95 \%$ using $5.3 \mathrm{~mol} / \mathrm{mmol}$ as cut-off for the spot urine.'

This should have stated:

'Using the 24-h urinary 5-HIAA as reference method, the AUC on ROC analysis for spot urinary 5-HIAA was 0.948 (95\% CI, $0.914-0.983 ; P<0.001$ ), attaining a sensitivity of $83 \%$ and specificity of $95 \%$ using $5.3 \mu \mathrm{mol} / \mathrm{mol}$ as cut-off for the spot urine.'

In the Results section on page 1084-1085, the original article stated:

'The median concentration of 5-HIAA measured in the spot urine was $4.9 \mathrm{~mol} / \mathrm{mmol}$ (IQR 2.26-16.4).'

'Based on the ROC analysis of 5-HIAA levels from patients both with NEN and without a diagnosis of NEN, a sensitivity of $83 \%$ and specificity of $95 \%$ was attained using $5.3 \mathrm{~mol} / \mathrm{mmol}$ as cut-off point for the spot urine.'

'Eight patients with NEN had levels of spot urine 5-HIAA below $5.3 \mathrm{~mol} / \mathrm{mmol}$ (median 3.4, range 2.3-4.8 mol/mmol) in the presence of slightly increased 24-h urinary 5-HIAA (median 52, range 46-110, $\mu \mathrm{mol} / 24 \mathrm{~h}$ ).'

This should have stated:

'The median concentration of 5-HIAA measured in the spot urine was $4.9 \mu \mathrm{mol} / \mathrm{mol}$ (IQR 2.26-16.4).'

'Based on the ROC analysis of 5-HIAA levels from patients both with NEN and without a diagnosis of NEN, a sensitivity of $83 \%$ and specificity of $95 \%$ was attained using $5.3 \mu \mathrm{mol} / \mathrm{mol}$ as cut-off point for the spot urine.'

'Eight patients with NEN had levels of spot urine 5-HIAA below $5.3 \mu \mathrm{mol} / \mathrm{mol}$ (median 3.4, range 2.3-4.8 $\mu \mathrm{mol} / \mathrm{mol}$ ) in the presence of slightly increased 24-h urinary 5-HIAA (median 52, range 46-110, $\mu \mathrm{mol} / 24 \mathrm{~h}$ ).'

In the Discussion section on page 1086, the original article stated:

'A cut-off of 5-HIAA measured in spot urine of $5.3 \mathrm{~mol} / \mathrm{mmol}$ showed a high sensitivity and specificity compared with the ULN value of 5-HIAA measured in the 24-h urine collection.'

This should have stated:

'A cut-off of 5-HIAA measured in spot urine of $5.3 \mu \mathrm{mol} / \mathrm{mol}$ showed a high sensitivity and specificity compared with the ULN value of 5-HIAA measured in the 24-h urine collection.'

The corrected Fig. 1 artwork and text legend are given in full below:

https://ec.bioscientifica.com

https://doi.org/10.1530/EC-19-0269e (c) 2020 The authors Published by Bioscientifica Ltd

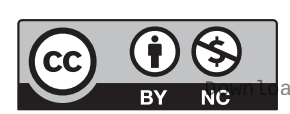

This work is licensed under a Creative Commons Attribution-NonCommercial 4.0 International License. ded from Bioscientifica.com at 04/26/2023 09:59:23AM 

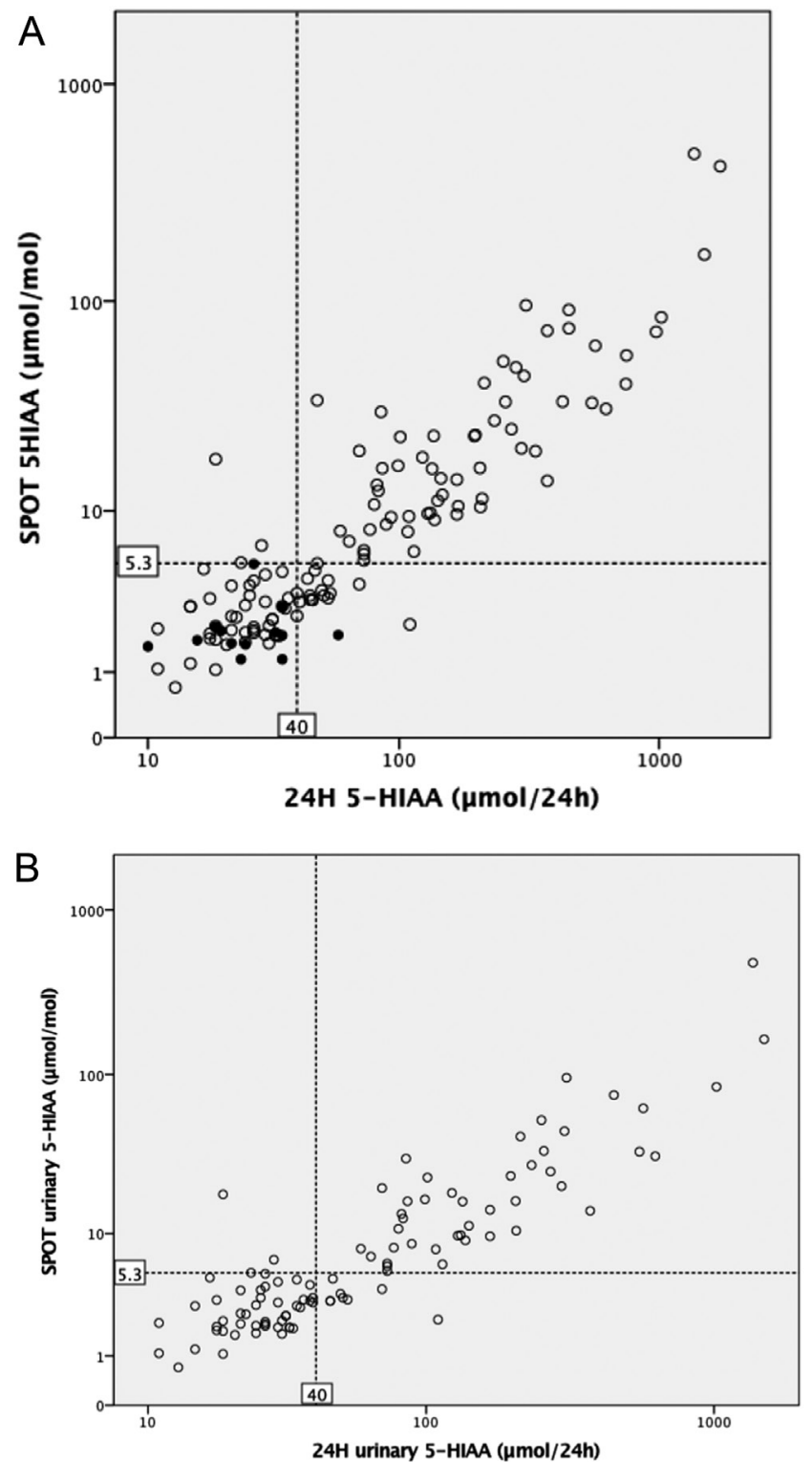

\section{Figure 1}

Correlation between the 5-HIAA values measured in the 24-h urine and the spot urine for the total number of measurements in patients with and without a NEN diagnosis (A) and including one sample per patient from the group of patients with NEN (B). 5-HIAA values are plotted using logarithmic $\left(\log _{10}\right)$ scale. The upper normal range for 24-h urinary 5-HIAA of $40 \mu \mathrm{mol} / 24 \mathrm{~h}$ and the suggested cut-off for the spot urinary 5-HIAA of $5.3 \mu \mathrm{mol} / \mathrm{mol}$ are shown by dashed lines. The white and black circles represent the measurements of patients, respectively, with and without a NEN diagnosis. 